\title{
Impact of wood-derived biochar on the hydraulic characteristics of compacted soils: Its influence on simulated farmland carbon sequestration
}

\author{
Ahmed Ahmed ${ }^{\circ *}$, Jiby Kurian ${ }^{\circledR}$, Sri Satyanarayana, and Vijaya Raghavan ${ }^{\circledR}$ \\ Department of Bioresource Engineering, McGill University, Macdonald Stewart Building 21, 111 Lakeshore road, \\ Saint-Anne-De-Bellevue, Quebec, Canada H9X 3V9
}

Received January 26, 2021; accepted April 19, 2021

\begin{abstract}
The addition of biochar is often proposed to increase agricultural soil quality and crop yield, while at the same time sequestering carbon from the atmosphere to help mitigate global climate change. In this research, the pore-size distribution, and saturated hydraulic conductivity of sandy loam and clay loam soils amended with varying dosages (0-10\% dry basis) and two different particle sizes (0.5-420 $\mu \mathrm{m}$ (PS1) or 421-841 $\mu \mathrm{m}$ (PS2)) of wood-derived biochar were investigated under compacted conditions $(5,10$, or 15 standard Proctor rammer blows $(5 \mathrm{~B}, 10 \mathrm{~B}$, or $15 \mathrm{~B}$, respectively)). In the $5 \mathrm{~B}$ compacted SL (SL-5B) soil, the volume of the soil fissures and transmission pores decreased, while the volume of the storage pores (SP) increased with increasing wood-derived biochar dosage. $23.1 \pm 0.9 \%$ of the volume of the $5 \mathrm{~B}$ compacted clay loam (CL-5B) are storage pores, this value increased to $27.4 \pm 2.0 \%$ upon amendment with $10 \%$ PS1. The saturated hydraulic conductivity of the sandy loam-5B soil amended with $10 \%$ PS 1 decreased from $6.8 \pm 0.3$ to $0.80 \pm 0.03 \mathrm{~mm} \mathrm{~h}^{-1}$. The sandy loam farmland $\mathrm{C}$ emissions decreased by $0.071 \mathrm{tC} \mathrm{ha}^{-1} \mathrm{y}^{-1}$, whereas CL farmland C emissions decreased by $0.091 \mathrm{tC} \mathrm{ha}^{-1} \mathrm{y}^{-1}$.

Keywords: soil biochar mixture, water retention, pore-size distribution, hydraulic conductivity, carbon sequestration
\end{abstract}

\section{INTRODUCTION}

Amendment of soil with biochar-charcoal produced through the pyrolysis or gasification of biomass under anaerobic conditions-improves soil structure and creates pores (Atkinson et al., 2010). Pyrolysis is the thermal decomposition of the volatile components of an organic

*Corresponding author e-mail: Ahmed.ahmed@mail.mcgill.ca substance, in the temperature range of $200-760^{\circ} \mathrm{C}$, by an indirect source of heat in the absence of air, forming syngas and liquids. A mixture of unreacted carbon (C) char remains as a residual material. However, gasification occurs at a higher temperature range of $480-1,650^{\circ} \mathrm{C}$ through the effect of heat supplied directly by the partial oxidation of $\mathrm{C}$ in the feedstock with very little air. In addition to the thermal decomposition of the volatile components of the substance, the non-volatile char is converted to additional syngas (Stahl et al., 2000). Soils amended with biochar show an increase in surface area and porosity, and a reduction in bulk density $(\rho)$ (Hardie et al., 2014; Herath et al., 2013). Therefore, the hydrological characteristics of the soil such as available water capacity (AWC), soil moisture retention, and hydraulic conductivity are improved by biochar amendment (Jien and Wang, 2013). However, the influence of biochar on soil AWC is not always positive (Hardie et al., 2014). (Tryon, 1948; Mukherjee and Lal, 2013) observed a decrease in AWC when biochar was applied in powdered form to fine-textured soils. The direct contribution of biochar to soil hydraulic properties due to its intrinsic characteristics is also documented in the literature (Andrenelli et al., 2016). Asai et al. (2009) found that clay soil with $48 \%$ clay and $18 \%$ sand underwent an increase in saturated hydraulic conductivity $\left(K_{\text {sat }}\right)$ when wood-derived biochar (WBC) was amended at $16 \mathrm{t} \mathrm{ha}^{-1}$. Eastman (2011) 
found no improvement in terms of water retention, despite the addition of biochar with a high proportion of micropores. Despite the growing number of studies concerning the influence of biochar on the hydraulic characteristics of agricultural soil, the influence of particle size of WBC on soil pore-size distribution and $K_{\text {sat }}$ remains unclear, especially for compacted agricultural soils.

WBC amendment may also allow the soil to serve as a $\mathrm{C}$ sink to aid in climate change mitigation. According to Lal (2007): "Terrestrial C sequestration can be defined as the capture and secure storage of atmospheric $\mathrm{C}$ in biotic and pedologic $\mathrm{C}$ pools that would otherwise be emitted to or remain in the atmosphere." The global mean soil storagerate in agricultural soils is estimated to be $1 \mathrm{tC} \mathrm{ha}^{-1} \mathrm{y}^{-1}$ (Smith et al., 2016). When biochar is applied at a depth of $30 \mathrm{~cm}$ to an agricultural farm it can potentially reduce up to $12 \%$ of equivalent emission from the farm (Woolf et al., 2010). WBC has an aromatic structure which is resistant to microbial degradation and therefore it has a higher potential for C sequestration (Hansen et al., 2015). Sequestering $\mathrm{C}$ in soils could significantly reduce atmospheric carbon dioxide $\left(\mathrm{CO}_{2}\right)$ concentrations (Smith et al., 1997). Incorporating biochar into agricultural soils may restore the soil organic $\mathrm{C}$ content, thereby improving soil fertility (Lal, 2009) and increasing crop yields (Jeffery et al., 2011). A one $\mathrm{tC} \mathrm{ha}^{-1}$ increase in soil $\mathrm{C}$ storage increased wheat yield by $4 \mathrm{t} \mathrm{ha}^{-1}(\mathrm{Lal}, 2004)$. Biochar also contributes to the cation exchange capacity of the soil, which is vital for nutrient retention (Abdollahi et al., 2014). The potential for negative emissions from soil $\mathrm{C}$ sequestration due to the enhanced hydraulic characteristics of the soil is still unclear.

In our study, we attempt to understand how the variations in wood derived biochar particle sizes and their composition in soils will influence the bulk density and hydraulic conductivity of two texturally different compacted soils. Therefore, it would be useful in the management of compacted soils for construction or agricultural purposes by providing an insight into which biochar particle size is suitable for a particular soil management scenario. Therefore, the first objective of this study was to investigate how the variation in WBC particle size could influence the pore-size distribution and water flow through compacted agricultural soils. The second objective of our research was to evaluate the implication of amending farmland with WBC with reference to the amount of $\mathrm{C}$ sequestered in the soil.

\section{MATERIALS}

The biochar (Maple Leaf ${ }^{\circledR}$ Charcoal, Charbon de Bois Feuille d'Érable Inc., Sainte-Christine d'Auvergne, QC) used in this study was purchased from the local market. It was produced by the thermal decomposition of forest wood waste, including maple (Acer sp.) wood, at $500^{\circ} \mathrm{C}$. The san- dy loam (SL) and clay loam (CL) soils were collected from the A horizon ( $0-0.2 \mathrm{~m}$ depth) of two texturally contrasting fields $\left(45^{\circ} 25^{\prime} 35.5^{\prime \prime} \mathrm{N}, 73^{\circ} 55^{\prime} 37.0^{\prime \prime} \mathrm{W}\right.$ and $45^{\circ} 25^{\prime} 35.8^{\prime \prime} \mathrm{N}$, $73^{\circ} 56^{\prime} 21.1^{\prime \prime} \mathrm{W}$ respectively) at the Macdonald Campus Farm, McGill University (Sainte-Anne-de-Bellevue, QC). The soil was air-dried at room temperature and then sieved to pass through a $2 \mathrm{~mm}$ sieve.

\section{METHODS}

Soil particle-size analysis was quantified according to ASTM D7928-17 (ASTM International, 2017a). The smallest particle size of the biochar was determined through laser diffraction analysis following the procedures outlined in (Müller et al., 2004) by using a laser diffraction sensor (SympaTEC-HELOS/BF, Clausthal-Zellerfeld, Germany).

The biochar was ground using a blender and sieved under a fume hood to achieve the desired particle sizes. Dry soil and biochar were mixed on a dry weight basis for 20 minutes using a soil mixer to obtain a homogeneous mixture.

The SL and CL soils were wetted in separate samples to reach their optimum moisture content for maximum compaction and then compacted in a Proctor compaction mould with five, ten, or fifteen rammer blows $(5 \mathrm{~B}, 10 \mathrm{~B}$, or $15 \mathrm{~B}$ respectively). The samples were taken from the compaction mould in order to measure soil water retention in the pressure plates.

The soil water content $(\theta)$ at saturation and at eight soil matric potentials (also known as hydraulic head $h)(-10$, $-30,-70,-100,-300,-500,-1,000$, and $-1,500 \mathrm{kPa})$ were determined with a pressure plate extractor following ASTM D6836-16 (ASTM International, 2017b). Soil $\rho$ values at the end of the test were determined using the method devised by (Blake et al., 1986), which was then used to convert the moisture content from a gravimetric basis $\left(\theta_{\mathrm{d}}\right)$ to a volumetric basis $(\theta)$ according to Eq. (1) (Gardner, 1986):

$$
v=\theta_{d} \frac{\rho}{\rho_{w}}
$$

where: $\rho_{w}$ is the density of water.

The water retention data were fitted with hydrologic software RETC (van Genuchten et al., 1991) in order to determine the shape parameters of the soil water retention characteristic curves (SWRCs) $(\alpha, n$ and $m)$ and then the soil pore-size distribution. The reciprocal of $\alpha$ accounts for the soil air entry pressure, whereas $n$ represents the slope of the curve which increases as the soil texture becomes coarser (Leij et al., 1992). In order to reduce the number of parameters estimated by the RETC code $m$ is set to equal $[1-(1 / n)]$. The (van Genuchten, 1980) model was chosen to simulate the water flow process in the soil (Eq. (2)). The root-mean-square error (RMSE) between the model prediction and the observed water retention data is minimized through the RETC code as a fitting process using the least square approach as described by Rasoulzadeh (2010). 


$$
S_{e}=\frac{1}{1+(\alpha|h|)^{n}},
$$

where: $S_{e}$ is the degree of saturation in the soil $=\left(\theta_{d}-\theta_{r}\right)$ / $\left(\theta_{s}-\theta_{r}\right) ; \theta_{\mathrm{s}}$ is the soil moisture content at saturation $(\%), \theta_{r}$ is the residual soil moisture content, and $\theta_{d}$ is the soil moisture content $(\%)$ at $|\mathrm{h}|$ suction pressure $(\mathrm{kPa})$.

The pore-size distribution was determined following the simplified Young-Laplace empirical equation (Eq. (3)) (Marquardt, 1963).

$$
D=\frac{30}{|h|},
$$

where: $D$ is the equivalent diameter of cylindrical pores in $\mu \mathrm{m}$ and $h$ is the matric potential expressed in metres of water $\left(\mathrm{m}_{\mathrm{w}}\right)\left(\mathrm{m}_{\mathrm{w}}=10^{-1} \mathrm{kPa}\right)$. Therefore, the fissure (FS) $D$ is greater than $500 \mu \mathrm{m}\left(h \leq-0.06 \mathrm{~m}_{\mathrm{w}}\right)$, the transmission pore (TP) $D$ is $50-500 \mu \mathrm{m}\left(0.06<h<1.6 \mathrm{~m}_{\mathrm{w}}\right)$, the storage pore (SP) $D$ is $0.5-50 \mu \mathrm{m}\left(1.6<h<60 \mathrm{~m}_{\mathrm{w}}\right)$, and the residual pore (RP) $D$ is less than $0.5 \mu \mathrm{m}\left(h>60 \mathrm{~m}_{\mathrm{w}}\right)$ (Batchelor, 1967). The whole pore volume (WPV) of a sample is the sum of the FS, TP, SP, and RP. All data presented in this article are based on the volumetric moisture content (v) (Eq. (1)).

The experimental procedures from Batchelor (1967) for measuring the $K_{\text {sat }}$ of a disturbed compacted soil sample in the laboratory were followed.

The Environmental Policy Integrated Climate (EPIC, version 1102) is a field-scale model designed to simulate surface runoff, nutrient immobilization and uptake, and the crop yield of drainage fields. The Century-EPIC simulation software calculates the $\mathrm{C}$ sequestration potential of the soils from $\mathrm{C}$ mineralization rates. Based on climatic variables, soil texture, carbon concentration, and crop growth characteristics, the model projects the amount of soil carbon that will be sequestered in subsequent years. The EPIC model was employed to simulate soil management scenarios in order to determine soil carbon sequestration with two builtin sample fields - with conventional tillage and fertilizer management - that have similar characteristics to the CL and SL soils used in this project. Changes to the simulated field parameters of the soil $\rho, K_{\text {sat }}$, and pore volume were adjusted based on the findings of this research project to simulate the influence of the WBC amendment to farmland. Farmlands with soils that were close to the characteristics of the SL and CL soils in this study were chosen. The SL and CL fields chosen for the simulation have $7 \%$ clay and $68 \%$ sand and $42 \%$ clay and $12 \%$ sand, respectively.

Four factors were investigated in this study: 1) soil type (SL and CL), 2) WBC particle size (PS1 $=0.5-420 \mu \mathrm{m}$ and $\mathrm{PS} 2=421-841 \mu \mathrm{m}), 3) \mathrm{WBC}$ dosage $(0,3,6$, and $10 \%$ on a dry weight basis), and 4) compaction efforts of 5B, 10B, and $15 \mathrm{~B}$. Therefore, there are 126 samples in triplicate. Analysis of variance (ANOVA) and Duncan's Multiple Range Test was used for testing mean differences using
SAS software (version 9.2, SAS Institute, Cary, NC, USA). All of the levels of significance published in this article are $\mathrm{p} \leq 0.05$.

Throughout the manuscript an SL soil amended with $10 \%$ dry basis WBC having particle size ranges of 0.5 $420 \mu \mathrm{m}$ (PS1), which was compacted with 5 blows (5B) from a Proctor compaction rammer is abbreviated as SL-PS1-10\%-5B.

\section{RESULTS AND DISCUSSION}

A hydrometer analysis showed that the SL soil contained $5 \%$ clay, $20 \%$ silt, and $75 \%$ sand. By comparison, the CL soil contained $37 \%$ clay, $27 \%$ silt, and $26 \%$ sand.

SL and CL soil $\rho$ in the Proctor compaction mould increased with the increase in compaction efforts at all dosages $(0,3,6$, and $10 \%)$ (Table 1$)$. This increase in soils $\rho$ is due to the decrease in soil pore spaces and the rearrangement of soil particles in the soil matrix as a result of increased compaction efforts. It is expected, therefore, that water at a higher soil $\rho$ will be held more tightly.

The increase in the amendment dosage of PS1 or PS2 decreased the $\rho$ of the SL and CL soils at all dosages and compaction efforts, except for CL-PS2-3\%-5B, CL-PS2-3\%-10B, and CL-PS2-3\%-15B which did not differ from the CL-unamended-5B, CL-unamended-10B, and CL-unamended-15B respectively, and also, CL-PS26\%-10B and CL-PS2-6\%-15B which did not differ from CL-PS2-10\%-10B and CL-PS2-10\%-15B, respectively. PS2 did not influence the $\rho$ of the CL soil at dosages of $3 \%$ for all compaction efforts. At medium and high compaction efforts of 10B and 15B respectively, the influence of increasing the dosage of PS2 from 6 to $10 \%$ did not change the CL soil $\rho$ (Table1).

The amendment of PS1 or PS2 decreased the $\rho$ of the SL or CL soil at all compaction levels (being higher in the PS2 than the PS1 treated soils) (Table 2), except for CL-PS2-3\%-5B, CL-PS2-3\%-10B, and CL-PS2-3\%15B which did not differ from the CL-unamended-5B, CL-unamended-10B, and CL-unamended-15B respectively, and also the SL-PS1-10\%-10B, SL-PS1-6\%-15B, and SL-PS1-10\%-15B which did not differ from SL-PS2-10\%10B, SL-PS2-6\%-15B, and SL-PS2-10\%-15B respectively. As the compaction effort increases, the influence of PS1 in decreasing the $\rho$ of the SL as compared to the PS2 soil diminishes, whereas at all compaction efforts, the PS1 amended CL soil has a lower $\rho$ value than the PS2 amended CL soils (Table 2).

RETC is a computer code developed by (Leij et al., 1992) that uses several parametric models such as Brooks-Corey and van Genuchten for analysing the soil water retention and hydraulic conductivity functions of unsaturated soils. Van Genuchten (1980) developed another computer code based on the Levenberg-Marquart optimization algorithm for inverse modelling in order to estimate the parameters 
Table 1. Statistical analyses of the dry bulk densities of unamended sandy loam (SL) and clay loam (CL) soils and soils amended with various dosages $(3,6$ or $10 \%)$ of wood-derived biochar with a particle sizes range of $0.5-420 \mu \mathrm{m}$ (PS1) or 421-841 $\mu \mathrm{m}$ (PS2) at various compaction efforts of 5,10 or 15 blows $(5 \mathrm{~B}, 10 \mathrm{~B}$, or $15 \mathrm{~B}$, respectively) with the Proctor compacting rammer. Each value represents the average of the triplicates. The standard deviation is reported after each value

\begin{tabular}{|c|c|c|c|c|c|}
\hline \multirow{2}{*}{$\begin{array}{l}\text { Soil } \\
\text { type }\end{array}$} & \multirow{2}{*}{$\begin{array}{l}\text { Particle } \\
\text { size }\end{array}$} & \multirow{2}{*}{$\begin{array}{c}\text { Dosage } \\
(\%)\end{array}$} & \multicolumn{3}{|c|}{ Dry bulk density $\left(\mathrm{g} \mathrm{cm}^{-3}\right)$} \\
\hline & & & $5 \mathrm{~B}$ & $10 \mathrm{~B}$ & $15 \mathrm{~B}$ \\
\hline \multirow{8}{*}{ SL } & \multirow{5}{*}{ PS1 } & 0 & $1.28 \pm 0.02 \mathrm{a}(\mathrm{a})$ & $1.49 \pm 0.02 \mathrm{a}(\mathrm{b})$ & $1.53 \pm 0.02 \mathrm{a}(\mathrm{c})$ \\
\hline & & 3 & $1.24 \pm 0.01 \mathrm{~b}(\mathrm{a})$ & $1.36 \pm 0.02 b(b)$ & $1.48 \pm 0.01 \mathrm{~b}(\mathrm{c})$ \\
\hline & & 6 & $1.20 \pm 0.03 \mathrm{c}(\mathrm{a})$ & $1.32 \pm 0.02 \mathrm{c}(\mathrm{b})$ & $1.40 \pm 0.03 \mathrm{c}(\mathrm{c})$ \\
\hline & & 10 & $1.16 \pm 0.01 \mathrm{~d}(\mathrm{a})$ & $1.28 \pm 0.02 \mathrm{~d}(\mathrm{~b})$ & $1.32 \pm 0.03 \mathrm{~d}(\mathrm{c})$ \\
\hline & & 0 & $1.28 \pm 0.02 \mathrm{a}(\mathrm{a})$ & $1.49 \pm 0.02 \mathrm{a}(\mathrm{b})$ & $1.53 \pm 0.02 \mathrm{a}(\mathrm{c})$ \\
\hline & \multirow{3}{*}{ PS2 } & 3 & $1.25 \pm 0.01 \mathrm{~b}(\mathrm{a})$ & $1.42 \pm 0.01 \mathrm{~b}(\mathrm{~b})$ & $1.50 \pm 0.01 b(\mathrm{c})$ \\
\hline & & 6 & $1.22 \pm 0.02 \mathrm{c}(\mathrm{a})$ & $1.38 \pm 0.03 \mathrm{c}(\mathrm{b})$ & $1.41 \pm 0.02 \mathrm{c}(\mathrm{c})$ \\
\hline & & 10 & $1.17 \pm 0.01 \mathrm{~d}(\mathrm{a})$ & $1.29 \pm 0.02 \mathrm{~d}(\mathrm{~b})$ & $1.34 \pm 0.03 \mathrm{~d}(\mathrm{c})$ \\
\hline \multirow{8}{*}{$\mathrm{CL}$} & \multirow{4}{*}{ PS1 } & 0 & $1.24 \pm 0.02 \mathrm{a}(\mathrm{a})$ & $1.41 \pm 0.02 \mathrm{a}(\mathrm{b})$ & $1.48 \pm 0.02 \mathrm{a}(\mathrm{c})$ \\
\hline & & 3 & $1.20 \pm 0.01 \mathrm{~b}(\mathrm{a})$ & $1.38 \pm 0.02 b(b)$ & $1.40 \pm 0.02 \mathrm{~b}(\mathrm{c})$ \\
\hline & & 6 & $1.09 \pm 0.03 \mathrm{c}(\mathrm{a})$ & $1.23 \pm 0.01 \mathrm{c}(\mathrm{b})$ & $1.30 \pm 0.02 \mathrm{c}(\mathrm{c})$ \\
\hline & & 10 & $1.02 \pm 0.03 \mathrm{~d}(\mathrm{a})$ & $1.19 \pm 0.03 \mathrm{~d}(\mathrm{~b})$ & $1.24 \pm 0.01 \mathrm{~d}(\mathrm{c})$ \\
\hline & \multirow{4}{*}{ PS2 } & 0 & $1.24 \pm 0.02 \mathrm{a}(\mathrm{a})$ & $1.41 \pm 0.02 \mathrm{a}(\mathrm{b})$ & $1.48 \pm 0.02 \mathrm{a}(\mathrm{c})$ \\
\hline & & 3 & $1.22 \pm 0.02 \mathrm{a}(\mathrm{a})$ & $1.38 \pm 0.02 \mathrm{a}(\mathrm{b})$ & $1.45 \pm 0.03 \mathrm{a}(\mathrm{c})$ \\
\hline & & 6 & $1.17 \pm 0.01 \mathrm{~b}(\mathrm{a})$ & $1.29 \pm 0.01 \mathrm{~b}(\mathrm{~b})$ & $1.40 \pm 0.03 \mathrm{~b}(\mathrm{c})$ \\
\hline & & 10 & $1.07 \pm 0.01 \mathrm{c}(\mathrm{a})$ & $1.30 \pm 0.01 \mathrm{~b}(\mathrm{~b})$ & $1.38 \pm 0.01 b(\mathrm{c})$ \\
\hline
\end{tabular}

Numbers followed by same letters: implies no differences in the same column, in parenthesis implies no differences in the same row.

of the aforementioned soil water retention functions using the $\mathrm{C}++$ programming language. Rasoulzadeh (2010) indicated that the correlation matrix for the van Genuchten and Brooks and Corey equations showed that the parameters of these equations were almost completely interdependent while the parameters of the double-exponential equation were less interdependent in relative terms.

The volumetric moisture contents at saturation for the SL and CL soils are 0.32 and $0.48 \mathrm{~cm}^{3} \mathrm{~cm}^{-3}$ and for the residual pores of 0.09 and $0.18 \mathrm{~cm}^{3} \mathrm{~cm}^{-3}$, respectively. The RMSE of the fitted curve in the RETC ranges from 1 to 1.7 $* \mathrm{e}^{-4} \mathrm{~cm}^{3} \mathrm{~cm}^{-3}$ for the SL soil and from 0.4 to $0.8 * \mathrm{e}^{-4} \mathrm{~cm}^{3}$ $\mathrm{cm}^{-3}$. This low RMSE is assumed to be negligible therefore, the RMSE was not taken into account when comparing the means.

The values of the model parameters differed between treatments with reference to $\alpha^{-1}$ (i.e. SL-unamended-5B = $6.7 \pm 3.4 \mathrm{kPa} v s$ SL-PS1-10\%-5B $=15.4 \pm 4.8 \mathrm{kPa}$ ) but not in the $n$ parameter (i.e. SL-unamended-5B $=1.83 \pm 0.04 v s$ SL-PS1-10\%-5B = 1.81 \pm 0.09$)$. With a higher $\alpha^{-1}$ value, a wider capillary saturation zone is evident in the amended soils. The $\alpha^{-1}$ values increased primarily due to the increase in air entry pressure when soils are more compacted. The $n$ value represents the slope of the soil water retention curve (SWRC) which increases as the soil texture becomes coarser. The $n$ value did not differ between treatments, which means that the soils did not change texture upon amendment. The water content within the residual pores (RP) (pores $<0.5 \mu \mathrm{m}$ ) estimated using RETC did not change in all treatments (i.e. RP of the SL is $9.6 \pm 2.2 \%$ and $\mathrm{CL}$ is $22.8 \pm 1.7 \%$ ) because, at high $h$ values the soil texture mainly controls soil hydrologic behaviour regardless of the WBC particle sizes or dosages (Greenland, 1977). These results confirm that the main purpose of WBC addition to soil is to influence the soil structural characteristics of pores $>0.2 \mu \mathrm{m}$.

Results from the soil pore-size distribution analysis show that the SL soil whole pore volume (WPV), FS and TP decreased when the force of the compaction blows increased $(5 \mathrm{~B}, 10 \mathrm{~B}$ or $15 \mathrm{~B})$ for all treatments $(0,3,6$ or $10 \%$ ) (Table 3). When the SL-unamended soil was more compacted, there were no changes in the SP. By contrast, at dosages of $3 \%, 6 \%$ or $10 \%$ in the amended SL soil the $\mathrm{SP}$ decreased with increasing compaction efforts. This may be attributed to the ability of the WBC amended SL soil to absorb more moisture at high dosages however, under suction pressure the water is released faster because of the pore water held by the WBC-amended SL soil. It may be deduced that the FS and TP volume of the SL soil decreased due to compaction which leads to lower $K_{\text {sat }}$ values for compacted SL soil. 
Table 2. Statistical analysis of the dry bulk densities of unamended sandy loam (SL) and clay loam (CL) soils and soils amended at the same dosages $(3,6$ or 10\%) of wood-derived biochar particle sizes with a range of $0.5-420 \mu \mathrm{m}$ (PS1) or 421-841 $\mu \mathrm{m}$ (PS2) at various compaction efforts of 5,10 or 15 blows $(5 \mathrm{~B}, 10 \mathrm{~B}$, or $15 \mathrm{~B}$, respectively) with the Proctor compacting rammer. Each value represents the average of triplicates. The standard deviation is reported after each value

\begin{tabular}{|c|c|c|c|c|c|}
\hline \multirow{2}{*}{$\begin{array}{l}\text { Soil } \\
\text { type }\end{array}$} & \multirow{2}{*}{ Particle size } & \multirow{2}{*}{$\begin{array}{c}\text { Dosage } \\
(\%)\end{array}$} & \multicolumn{3}{|c|}{ Dry bulk density $\left(\mathrm{g} \mathrm{cm}^{-3}\right)$} \\
\hline & & & $5 B$ & $10 \mathrm{~B}$ & $15 \mathrm{~B}$ \\
\hline \multirow{9}{*}{ SL } & unamended & & $1.28 \pm 0.02 \mathrm{a}$ & $1.49 \pm 0.02 \mathrm{a}$ & $1.53 \pm 0.02 \mathrm{a}$ \\
\hline & PS1 & 3 & $1.24 \pm 0.01 \mathrm{~b}$ & $1.36 \pm 0.02 b$ & $1.48 \pm 0.01 \mathrm{~b}$ \\
\hline & PS2 & & $1.25 \pm 0.01 \mathrm{c}$ & $1.42 \pm 0.01 \mathrm{c}$ & $1.50 \pm 0.01 \mathrm{c}$ \\
\hline & unamended & & $1.28 \pm 0.02 \mathrm{a}$ & $1.49 \pm 0.02 \mathrm{a}$ & $1.53 \pm 0.02 \mathrm{a}$ \\
\hline & PS1 & 6 & $1.20 \pm 0.03 b$ & $1.32 \pm 0.02 b$ & $1.40 \pm 0.03 \mathrm{~b}$ \\
\hline & PS2 & & $1.22 \pm 0.02 \mathrm{c}$ & $1.38 \pm 0.03 \mathrm{c}$ & $1.41 \pm 0.02 \mathrm{~b}$ \\
\hline & unamended & & $1.28 \pm 0.02 \mathrm{a}$ & $1.49 \pm 0.02 \mathrm{a}$ & $1.53 \pm 0.02 \mathrm{a}$ \\
\hline & PS1 & 10 & $1.16 \pm 0.01 \mathrm{~b}$ & $1.28 \pm 0.02 b$ & $1.32 \pm 0.03 \mathrm{~b}$ \\
\hline & PS2 & & $1.17 \pm 0.01 \mathrm{c}$ & $1.29 \pm 0.02 b$ & $1.34 \pm 0.03 b$ \\
\hline \multirow{9}{*}{$\mathrm{CL}$} & unamended & & $1.24 \pm 0.02 \mathrm{a}$ & $1.41 \pm 0.02 \mathrm{a}$ & $1.48 \pm 0.02 \mathrm{a}$ \\
\hline & PS1 & 3 & $1.20 \pm 0.01 \mathrm{~b}$ & $1.38 \pm 0.02 b$ & $1.40 \pm 0.03 \mathrm{~b}$ \\
\hline & PS2 & & $1.22 \pm 0.02 \mathrm{a}$ & $1.38 \pm 0.02 \mathrm{a}$ & $1.45 \pm 0.03 \mathrm{a}$ \\
\hline & unamended & & $1.24 \pm 0.02 \mathrm{a}$ & $1.41 \pm 0.03 \mathrm{a}$ & $1.48 \pm 0.02 \mathrm{a}$ \\
\hline & PS1 & 6 & $1.09 \pm 0.03 \mathrm{~b}$ & $1.23 \pm 0.01 \mathrm{~b}$ & $1.30 \pm 0.02 \mathrm{~b}$ \\
\hline & PS2 & & $1.17 \pm 0.01 \mathrm{c}$ & $1.29 \pm 0.01 \mathrm{c}$ & $1.40 \pm 0.03 \mathrm{c}$ \\
\hline & unamended & & $1.24 \pm 0.02 \mathrm{a}$ & $1.41 \pm 0.02 \mathrm{a}$ & $1.48 \pm 0.02 \mathrm{a}$ \\
\hline & PS1 & 10 & $1.02 \pm 0.03 \mathrm{~b}$ & $1.19 \pm 0.03 b$ & $1.24 \pm 0.01 \mathrm{~b}$ \\
\hline & PS2 & & $1.07 \pm 0.01 \mathrm{c}$ & $1.30 \pm 0.01 \mathrm{c}$ & $1.38 \pm 0.01 \mathrm{c}$ \\
\hline
\end{tabular}

Numbers followed by same letters implies no differences in the same column.

The WPV of the CL soil amended with $0,3,6$ or $10 \%$ PS1 or PS2 decreased due to compaction and resulted in a decrease in FS, TP, and SP.

The WPV of the SL-unamended-5B soil increased with an increase in the PS1 or PS2 dosage (Table 3). At a medium compaction effort of $10 \mathrm{~B}$, there was no change in the WPV between SL-PS1-6\%-10B and SL-PS1-10\%-10B. At a high compaction effort of $15 \mathrm{~B}$, there was no change in the WPV between any treatment. The FS and TP of the SL-unamended-15B soil decreased with 3\% PS1 or PS2 but there is no difference between the FS and TP of SL 15B compacted soils between dosages. The volume of SP in the SL-unamended soil increased for all amendment rates (i.e., 3,6 and 10\%) with PS1 or PS2 except for PS1-3\%-15B, PS2-3\%-15B, PS2-6\%-15B which did not change from the unamended SL soil. When the PS1 dosage increases the SP in the SL soil increases, these results were sustained for all compaction efforts and high dosages. Thus, the new pores created in the SL soil due to PS1 or PS2 incorporation were between $0.5-50 \mu \mathrm{m}$ but with elevated compaction efforts i.e. at $10 \mathrm{~B}$ or $15 \mathrm{~B}$, the effect of PS1 or PS2 dosages on the soil pores diminishes especially at lower dosages of $3 \%$. The FS and TP decreased when WBC dosages increased in the SL soil but, at relatively higher compaction efforts, the effect of the WBC dosage on decreasing FS and TP and increasing the SP was diminished because of the influence of the compaction efforts on the decreasing of the larger soil pores.

The statistical analysis in Table 3 showed that the PS1 amendment to the CL-unamended-5B soil only increased the WPV of the treated soil at the 5B compaction effort at dosages of $6 \%$ with no difference between the $6 \%$ and $10 \%$ dosages. The volume of the pores within the FS and TP class increased by up to $30 \%$ over the unamended CL soil when PS1-6\% or PS1-10\% was applied to the CL soil. Therefore, the increase in the WPV is due to an increase in the FS and TP, in the pore size range $>50 \mu \mathrm{m}$, but not in the SP. At medium and higher compaction efforts of $10 \mathrm{~B}$ and $15 \mathrm{~B}$, there was no change in the WPV, FS, TP or SP at any dosage.

The PS2 amendment increased the SP of the SL-unamended-5B soil, by a lower degree than PS1 at all dosages (Table 4). At the higher compaction efforts of 10B and $15 \mathrm{~B}$ and at medium and high dosages (6 and 10\%), the particle size of WBC did not have any influence in differentiating the SP of the SL soil. The PS2 amendment 


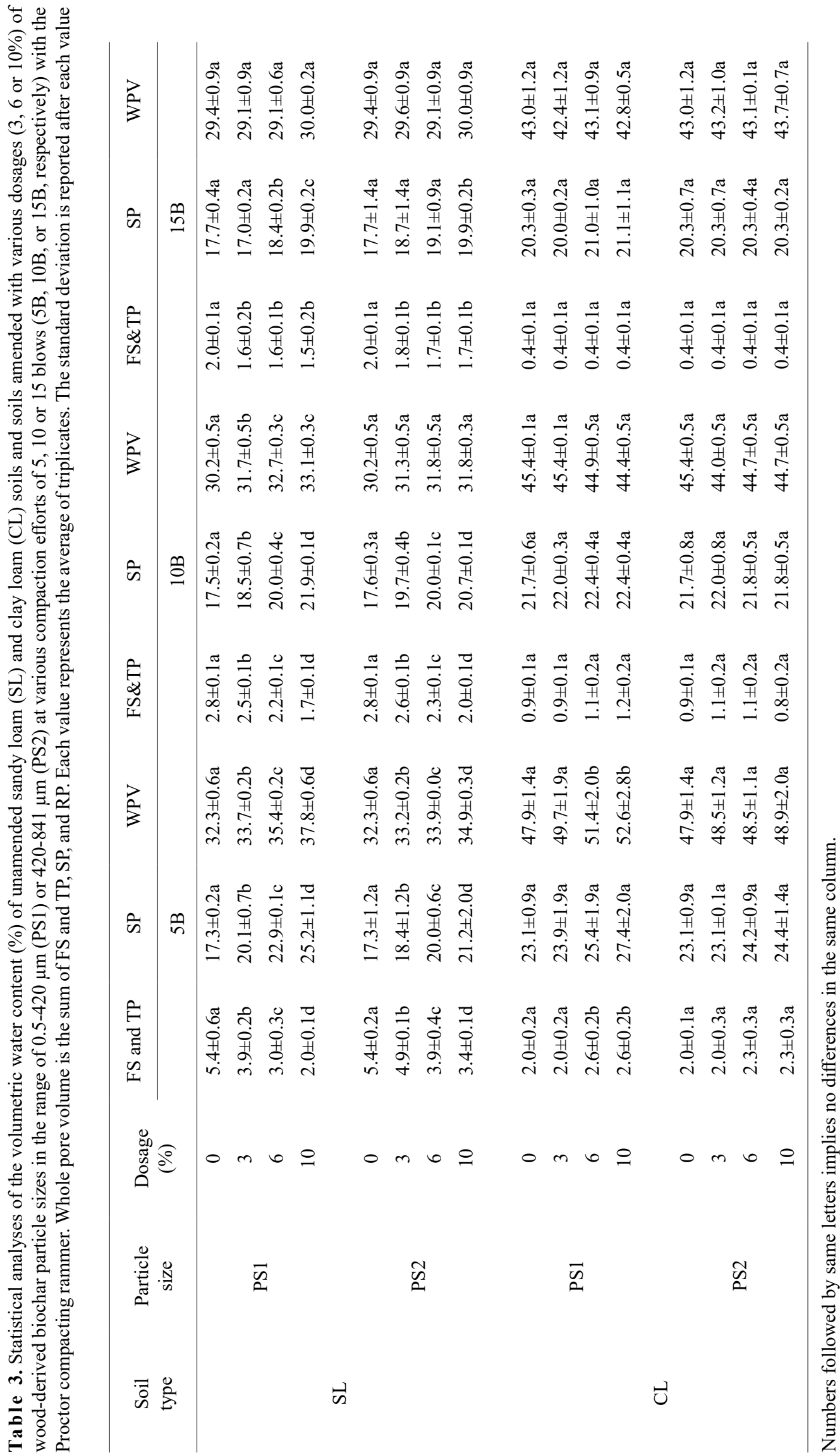




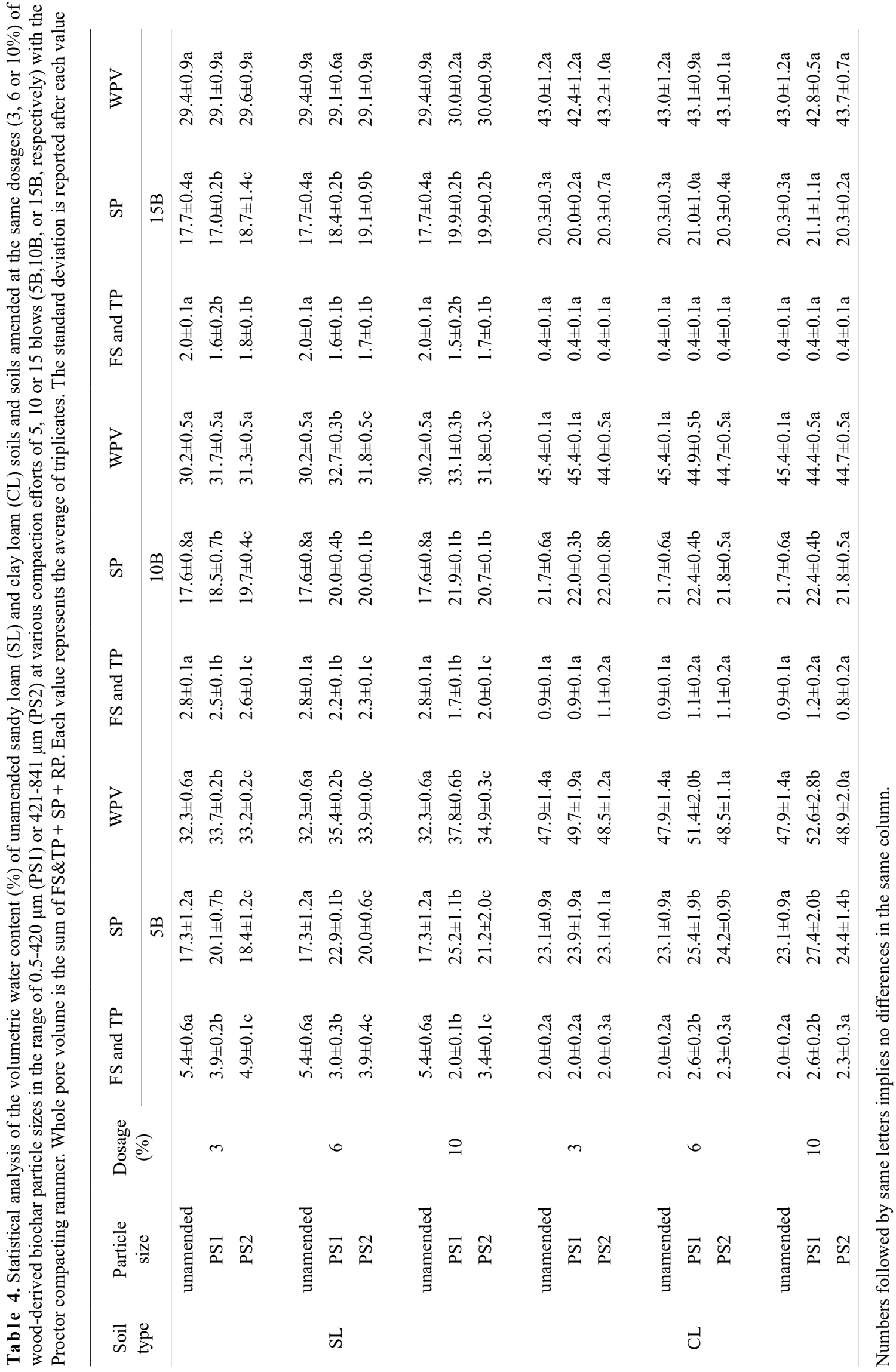


decreased the FS and TP of the SL-unamended-5B and SL-unamended-10B soil, at a lower degree than the PS1 at all dosages. At high compaction efforts of 15B, the particle size of WBC did not have any influence in differentiating the FS and TP from the SL soil. As the particle sizes of the WBC increased (from PS1 to PS2) at the same dosage, the effect on the soil pore structure was not sustained under medium and high compaction efforts of $10 \mathrm{~B}$ and $15 \mathrm{~B}$ respectively. For example, as the compaction effort increases, the influence of PS1 on further decreasing the SP of SL-PS2 diminishes at the 6 and 10\% dosages (Table 4).

There is no difference in FS and TP between the CL-unamended and CL soil amended with PS2 at any dosage. At PS1 dosages of 6 and 10\% the CL-unamended-5B FS and TP increased. At the medium compaction effort of $10 \mathrm{~B}$, the SP increases at 6 and $10 \%$ dosages of PS1. At 15B compaction effort, the CL soil did not show any changes at any pore-size range due to $\mathrm{WBC}$ amendment.

All in all, the particle sizes of the WBC incorporated into the soil matrix influence the volume of the soil pores differently. This variation may be attributed to the effect of the WBC particles being more hydrophobic than soil particles and when subjected to tension, more water is released, especially under low suction conditions, because the WBC particles lower the force of adhesion of soil particles to water.

The $K_{\text {sat }}$ statistical differences between unamended soils and soils amended with various dosages of PS1 or PS2 subjected to several different compaction efforts are presented in Table 5. Increasing the compaction effort from 5B to 15B decreased the $K_{\text {sat }}$ of the unamended SL (SL-unamended) soil from $6.80 \pm 0.30$ to $0.35 \pm 0.02 \mathrm{~mm} \mathrm{~h}^{-1}$ and the unamended CL (CL-unamended) soil from $0.25 \pm 0.07$ to $0.09 \pm 0.01$ $\mathrm{mm} \mathrm{h}^{-1}$ (Table 5). This reduction is due to the decline in the number of soil pores with compaction, which consequently decreased the flow of water in the soils. Therefore, it should be evident from the pore-size distribution analysis (in section 4.3.1) that both the FS and TP volume decreased in the soils when the compaction effort increased. At the same dosages of 3, 6, or $10 \%$, the $K_{\text {sat }}$ of the SL and CL soils decreased with the increase in compaction efforts. Ohu (1985) also found that the $K_{\text {sat }}$ of SL and CL soils decreased when the compaction level increased.

At 5B and 10B compaction efforts, the $K_{\text {sat }}$ of the SL-unamended-5B soil decreased with increasing dosages of PS1 or PS2 due to a decrease in the soil's pore geometry induced by the presence of WBC in the soil, because the

Table 5. Statistical analyses of the saturated hydraulic conductivity $\left(K_{\text {sat }}\right)$ of unamended sandy loam (SL) and clay loam (CL) soils and soils amended with various dosages (3, 6 or 10\%) of wood-derived biochar particle sizes with the range of $0.5-420 \mu \mathrm{m}$ (PS1) or 420-841 $\mu \mathrm{m}$ (PS2) at various compaction efforts of 5, 10 or 15 blows (5B, 10B, or 15B, respectively) with the Proctor compacting rammer. Each value represents the average of triplicates. The standard deviation is reported after each value

\begin{tabular}{|c|c|c|c|c|c|}
\hline \multirow{2}{*}{$\begin{array}{l}\text { Soil } \\
\text { type }\end{array}$} & \multirow{2}{*}{$\begin{array}{c}\text { Particle } \\
\text { size }\end{array}$} & \multirow{2}{*}{$\begin{array}{c}\text { Dosage } \\
(\%)\end{array}$} & \multicolumn{3}{|c|}{$K_{\text {sat }}\left(\mathrm{mm} \mathrm{h}^{-1}\right)$} \\
\hline & & & $5 \mathrm{~B}$ & 10B & 15B \\
\hline \multirow{8}{*}{ SL } & \multirow{5}{*}{ PS1 } & 0 & $6.80 \pm 0.30 \mathrm{a}(\mathrm{a})$ & $2.00 \pm 0.09 \mathrm{a}(\mathrm{b})$ & $0.35 \pm 0.02 \mathrm{a}(\mathrm{c})$ \\
\hline & & 3 & $1.31 \pm 0.80 \mathrm{~b}(\mathrm{a})$ & $0.68 \pm 0.04 b(b)$ & $0.17 \pm 0.02 b(c)$ \\
\hline & & 6 & $1.00 \pm 0.09 \mathrm{c}(\mathrm{a})$ & $0.60 \pm 0.05 \mathrm{c}(\mathrm{b})$ & $0.20 \pm 0.03 b(c)$ \\
\hline & & 10 & $0.80 \pm 0.03 \mathrm{~d}(\mathrm{a})$ & $0.35 \pm 0.10 \mathrm{~d}(\mathrm{~b})$ & $0.20 \pm 0.02 b(c)$ \\
\hline & & 0 & $6.80 \pm 1.88 \mathrm{a}(\mathrm{a})$ & $2.00 \pm 0.09 \mathrm{a}(\mathrm{b})$ & $0.35 \pm 0.02 \mathrm{a}(\mathrm{c})$ \\
\hline & \multirow{3}{*}{ PS2 } & 3 & $3.20 \pm 0.09 \mathrm{~b}(\mathrm{a})$ & $1.70 \pm 0.09 \mathrm{~b}(\mathrm{~b})$ & $0.27 \pm 0.02 \mathrm{~b}(\mathrm{c})$ \\
\hline & & 6 & $2.85 \pm 0.08 \mathrm{c}(\mathrm{a})$ & $1.00 \pm 0.07 \mathrm{c}(\mathrm{b})$ & $0.25 \pm 0.02 \mathrm{~b}(\mathrm{c})$ \\
\hline & & 10 & $2.20 \pm 0.08 \mathrm{~d}(\mathrm{a})$ & $0.47 \pm 0.05 \mathrm{~d}(\mathrm{~b})$ & $0.23 \pm 0.05 b(c)$ \\
\hline \multirow{8}{*}{ CL } & \multirow{4}{*}{ PS1 } & 0 & $0.25 \pm 0.12 \mathrm{a}(\mathrm{a})$ & $0.16 \pm 0.03 \mathrm{a}(\mathrm{b})$ & $\left.0.09 \pm 0.02 \mathrm{a}(\mathrm{c})^{* *}\right)$ \\
\hline & & 3 & $0.35 \pm 0.09 \mathrm{a}(\mathrm{a})$ & $0.18 \pm 0.03 \mathrm{a}(\mathrm{b})$ & $0.06 \pm 0.03 \mathrm{a}(\mathrm{c})$ \\
\hline & & 6 & $0.44 \pm 0.08 b(a)$ & $0.20 \pm 0.05 \mathrm{a}(\mathrm{b})$ & $0.06 \pm 0.03 \mathrm{a}(\mathrm{c})$ \\
\hline & & 10 & $0.50 \pm 0.09 b(a)$ & $0.20 \pm 0.01 \mathrm{a}(\mathrm{b})$ & $0.06 \pm 0.03 \mathrm{a}(\mathrm{c})$ \\
\hline & \multirow{4}{*}{ PS2 } & 0 & $0.25 \pm 0.07 \mathrm{a}(\mathrm{a})$ & $0.16 \pm 0.03 \mathrm{a}(\mathrm{b})$ & $0.09 \pm 0.01 \mathrm{a}(\mathrm{c})$ \\
\hline & & 3 & $0.30 \pm 0.05 \mathrm{a}(\mathrm{a})$ & $0.17 \pm 0.01 \mathrm{a}(\mathrm{b})$ & $0.09 \pm 0.03 \mathrm{a}(\mathrm{c})$ \\
\hline & & 6 & $0.28 \pm 0.03 \mathrm{a}(\mathrm{a})$ & $0.18 \pm 0.01 \mathrm{a}(\mathrm{b})$ & $0.09 \pm 0.01 \mathrm{a}(\mathrm{c})$ \\
\hline & & 10 & $0.30 \pm 0.04 \mathrm{a}(\mathrm{a})$ & $0.19 \pm 0.01 \mathrm{a}(\mathrm{b})$ & $0.09 \pm 0.02 \mathrm{a}(\mathrm{c})$ \\
\hline
\end{tabular}

Numbers followed by same letters: implies no differences in the same column, in parenthesis implies no differences in the same row. 
reduction in pore spaces reduces the movement of water through the soil (Table 5). The $K_{\text {sat }}$ of the SL-unamended-5B soil decreased by $88 \%$ with the PS1-10\% dosage. The drop in $K_{\text {sat }}$ values was higher at 3\% dosages (i.e. an $80.7 \%$ drop in $K_{\text {sat }}$ from SL-unamended-5B soil) than at the 6\% dosage (i.e. a $23.7 \%$ drop in $K_{\text {sat }}$ from SL-PS1-3\%-5B soil) or $10 \%$ dosage (i.e. a $20 \%$ reduction in $K_{\text {sat }}$ from SL-PS1-6\%-5B soil). This variation in $K_{\text {sat }}$ probably occurred because the finer PS1 particles occupied the voids of the soil at lower dosages rather than being located between soil particles.

Even though the WPV increased in the SL soil when amended with WBC (at low compacting efforts) the $K_{\text {sat }}$ decreased, because the volume of the FS and TP decreased whereas the volume of the SP increased. The increase in the volume of the SP was the reason for the increase in the WPV, which indicates that the addition of WBC to the SL soil created more pores in the range of 0.5-50 $\mu \mathrm{m}$.

At $15 \mathrm{~B}$ compaction effort, the $K_{\text {sat }}$ of the SL-unamended decreased with the amendment of PS1-3\% or PS2-3\%, with no difference between any amendment dosages (i.e. no difference between SL-PS1-3\%-PS1, SL-PS1-6\%-PS1, or SL-PS1-10\%-PS1). The SL soil particle rearrangement due to compaction created fewer pores in the range of 50-500 $\mu \mathrm{m}$, resulting in no significant decrease in $K_{\text {sat }}$ when WBC dosages increased.

The CL soil showed the opposite trend where the $K_{\text {sat }}$ increased when amended with either PS1-6\% or PS1-10\%. The $K_{\text {sat }}$ of the CL-unamended-5B soil amended with PS1$10 \%$ increased by $100 \%$. The CL-unamended-5B underwent no change when amended with 3\% PS1. Amendment with the PS2 did not change the $K_{\text {sat }}$ of the CL-unamended-5B soil under any treatment. This is because of the significant increase in both FS and TP in the 6 or $10 \%$ PS1 amendment dosage compared to no significant increase in FS and TP at the $3 \%$ dosage (as described in section 4.3.2). At medium and high compaction efforts of 10 and 15B there is no difference in $K_{\text {sat }}$ between any treatment.

The $K_{\text {sat }}$ statistical differences between the unamended soils and soils amended with either PS1 or PS2 at the same dosage are presented in Table 6 . The $K_{\text {sat }}$ of the unamended SL soil decreased when amended with either PS1 or PS2 at all dosages and compaction efforts. The PS1 amended SL soil has a lower $K_{\text {sat }}$ than the PS2 amended SL soil at all dosages with $5 \mathrm{~B}$ and $10 \mathrm{~B}$ compaction efforts and at

Table 6. Statistical analysis of the saturated hydraulic conductivity $\left(K_{\text {sat }}\right)$ of unamended sandy loam (SL) and clay loam (CL) soils and soils amended at the same dosages (3, 6 or 10\%) of wood-derived biochar particle sizes with the range of 0.5-420 $\mu \mathrm{m}$ (PS1) or 421-841 $\mu \mathrm{m}$ (PS2) at various compaction efforts of 5,10 or 15 blows $(5 \mathrm{~B}, 10 \mathrm{~B}$, or $15 \mathrm{~B}$ respectively) with the Proctor compacting rammer. Each value represents the average of triplicates. The standard deviation is reported after each value

\begin{tabular}{|c|c|c|c|c|c|}
\hline \multirow{2}{*}{$\begin{array}{l}\text { Soil } \\
\text { type }\end{array}$} & \multirow{2}{*}{$\begin{array}{l}\text { Particle } \\
\text { size }\end{array}$} & \multirow{2}{*}{$\begin{array}{c}\text { Dosage } \\
(\%)\end{array}$} & \multicolumn{3}{|c|}{$K_{\text {sat }}\left(\mathrm{mm} \mathrm{h}^{-1}\right)$} \\
\hline & & & $5 \mathrm{~B}$ & 10B & $15 \mathrm{~B}$ \\
\hline \multirow{9}{*}{ SL } & unamended & & $6.80 \pm 1.00 \mathrm{a}$ & $2.00 \pm 0.09 \mathrm{a}$ & $0.35 \pm 0.02 \mathrm{a}$ \\
\hline & PS1 & 3 & $1.31 \pm 0.80 \mathrm{~b}$ & $0.68 \pm 0.04 b$ & $0.17 \pm 0.02 b$ \\
\hline & PS2 & & $3.20 \pm 0.09 \mathrm{c}$ & $1.70 \pm 0.09 \mathrm{c}$ & $0.27 \pm 0.02 \mathrm{c}$ \\
\hline & unamended & & $6.80 \pm 1.00 \mathrm{a}$ & $2.00 \pm 0.09 a$ & $0.35 \pm 0.02 \mathrm{a}$ \\
\hline & PS1 & 6 & $1.00 \pm 0.39 b$ & $0.60 \pm 0.05 b$ & $0.20 \pm 0.03 b$ \\
\hline & PS2 & & $2.85 \pm 0.75 c$ & $1.00 \pm 0.07 \mathrm{c}$ & $0.25 \pm 0.02 b$ \\
\hline & unamended & & $6.80 \pm 1.00 \mathrm{a}$ & $2.00 \pm 0.09 \mathrm{a}$ & $0.35 \pm 0.02 \mathrm{a}$ \\
\hline & PS1 & 10 & $0.80 \pm 0.03 b$ & $0.35 \pm 0.10 \mathrm{~b}$ & $0.20 \pm 0.02 b$ \\
\hline & PS2 & & $2.20 \pm 0.08 \mathrm{c}$ & $0.47 \pm 0.05 \mathrm{c}$ & $0.23 \pm 0.05 \mathrm{~b}$ \\
\hline \multirow{9}{*}{$\mathrm{CL}$} & unamended & & $0.25 \pm 0.07 \mathrm{a}$ & $0.16 \pm 0.03 \mathrm{a}$ & $0.09 \pm 0.02 \mathrm{a}$ \\
\hline & PS1 & 3 & $0.35 \pm 0.08 \mathrm{a}$ & $0.18 \pm 0.03 \mathrm{a}$ & $0.06 \pm 0.03 \mathrm{a}$ \\
\hline & PS2 & & $0.30 \pm 0.05 \mathrm{a}$ & $0.17 \pm 0.01 \mathrm{a}$ & $0.09 \pm 0.03 \mathrm{a}$ \\
\hline & unamended & & $0.25 \pm 0.07 \mathrm{a}$ & $0.16 \pm 0.03 a$ & $0.09 \pm 0.01 \mathrm{a}$ \\
\hline & PS1 & 6 & $0.44 \pm 0.07 \mathrm{~b}$ & $0.20 \pm 0.05 a$ & $0.06 \pm 0.03 \mathrm{a}$ \\
\hline & PS2 & & $0.28 \pm 0.03 \mathrm{a}$ & $0.18 \pm 0.01 \mathrm{a}$ & $0.09 \pm 0.01 \mathrm{a}$ \\
\hline & unamended & & $0.25 \pm 0.07 \mathrm{a}$ & $0.16 \pm 0.03 a$ & $0.09 \pm 0.01 \mathrm{a}$ \\
\hline & PS1 & 10 & $0.50 \pm 0.09 \mathrm{~b}$ & $0.20 \pm 0.04 \mathrm{a}$ & $0.06 \pm 0.03 \mathrm{a}$ \\
\hline & PS2 & & $0.30 \pm 0.04 \mathrm{a}$ & $0.19 \pm 0.01 \mathrm{a}$ & $0.09 \pm 0.02 \mathrm{a}$ \\
\hline
\end{tabular}

Numbers followed by same letters implies no differences in the same column. 
a $3 \%$ dosage with the $15 \mathrm{~B}$ compaction effort. At the $15 \mathrm{~B}$ compaction effort, there was no difference in $K_{\text {sat }}$ between the PS1-6\% and PS2-10\% amended SL soil (this confirms the results of the analyses shown in section 4.3.3 where there were no changes in FS, TP and SP). The $K_{\text {sat }}$ of the CL-unamended-5B soil increased when amended with PS1 at $6 \%$ (CL-PS1-6\%-5B) or 10\% (CL-PS1-10\%-5B) dosages. There was no difference in the $K_{\text {sat }}$ between the PS1 and PS2 amended CL soil for any other treatment.

Varying the particle size of WBC influenced the $K_{\text {sat }}$ of the soils based on the soil texture. Only at high compaction values of $15 \mathrm{~B}$ can, varying the particle size of WBC at low dosages, influence $K_{\text {sat }}$ in the SL soil. On the other hand, under the low compaction effort of 5B, only the low dosage of PS1 can induce an increase in the $K_{\text {sat }}$ of the CL soil.

There are several biogeochemical models used to simulate crop production and for describing and quantifying the contribution of agricultural systems to $\mathrm{C}$ sequestration and GHG sink status such as: APSIM, CERES-EGC, DayCent, DNDC, DSSAT, EPIC, PaSim, RothC and STICS. A complete comparison is available in Brilli et al. (2017).

The EPIC model output demonstrated the differences in $\mathrm{C}$ mineralization between the management scenarios. The built in SL and CL farmlands that were chosen in the EPIC simulation have total $\mathrm{C}$ emissions of $0.532 \mathrm{tC} \mathrm{ha}^{-1} \mathrm{y}^{-1}$ and $0.720 \mathrm{tC} \mathrm{ha}^{-1} \mathrm{y}^{-1}$, respectively. If the same farmlands have a different bulk density and hydraulic conductivity induced in the case where PS1-10\% is incorporated in these simulated farmlands, they will release less $\mathrm{C}$. The SL and CL farmlands will experience a decrease in $\mathrm{C}$ emissions of 0.071 and $0.091 \mathrm{tC} \mathrm{ha}^{-1} \mathrm{y}^{-1}$ (13.3 and $12 \%$ decrease) respectively. This decrease in $\mathrm{C}$ emissions is due to changes in the hydraulic properties and bulk density induced in the amended soils if a $10 \% \mathrm{PS} 1$ is applied to the farmland. The $\mathrm{C}$ sequestration rate reported here is approximately double that estimated by Woolf et al. (2010) for a biochar amendment to the soil.

\section{CONCLUSIONS}

This research project has made a contribution to the state of knowledge concerning how the variation in WBC particle size may influence bulk density, hydraulic conductivity and pore-sizes distribution in SL and CL soils.

1. The addition of $\mathrm{WBC}$ to the soil increases its pore spaces. The particle sizes of WBC incorporated into the soil matrix seems to differentiate the extent of biochar contribution to soil pore sizes and saturated hydraulic conductivity based on the soil texture. These differences in pore creation may be attributed to whether WBC particles occupy soil pores or become situated between the soil particles based on soil texture and/or compaction effort.

2.The decrease in the farmland carbon losses may assist farmers in the process of adopting WBC in order to offset their $\mathrm{C}$ footprint.
Conflict of interest: The authors declare no conflict of interest.

\section{REFERENCES}

Abdollahi L., Schjønning P., Elmholt S., and Munkholm L.J., 2014. The effects of organic matter application and intensive tillage and traffic on soil structure formation and stability. Soil Till. Res., 136, 28-37.

https://doi.org/ 10.1016/j.still.2013.09.011

Andrenelli M., Maienza A., Genesio L., Miglietta F., Pellegrini S., Vaccari F., and Vignozzi N., 2016. Field application of pelletized biochar: Short term effect on the hydrological properties of a silty CL soil. Agric. Water Manag., 163, 190196. https://doi.org/10.1016/j.agwat.2015.09.017

Asai H., Samson B.K., Stephan H.M., Songyikhangsuthor K., Homma K., Kiyono Y., Inoue Y., Shiraiwa T., and Horie T., 2009. Biochar amendment techniques for upland rice production in Northern Laos: 1. Soil physical properties, leaf SPAD and grain yield. Field Crops Res., 111(1-2), 81-84. https://doi.org/10.1016/j.fcr.2008.10.008

ASTM International, 2017a. ASTM D7928-17, standard test method for particle-size distribution (gradation) of finegrained soils using the sedimentation (hydrometer) analysis. West Conshohocken, PA: ASTM International. https://doi. org/10.1520/D7928-17

ASTM International, 2017b. ASTM D6836-16, standard test methods for determination of the soil water characteristic curve for desorption using hanging column, pressure extractor, chilled mirror hygrometer, or centrifuge. West Conshohocken, PA: ASTM International. https://doi 10.1520/D6836-16

Atkinson C.J., Fitzgerald J.D., and Hipps N.A., 2010. Potential mechanisms for achieving agricultural benefits from biochar application to temperate soils: a review. Plant Soil, 337(1-2), 1-18. https://doi.org/10.1007/s11104-010-0464-5

Batchelor G.K., 1967. An Introduction to Fluid Dynamics. Cambridge University Press, New York.

Blake G.R. and Hartge K.H., 1986. Bulk density. In: Methods of Soil Analysis. Part 1, Physical and Mineralogical Methods (Ed. A. Klute). Agronomy Monograph 9, American Society of Agronomy and Soil Science Society of America, Madison, WI, 363-375. https://doi.org/10.2136/sssabookser5.1.2ed.c15

Brilli L., Bechini L., Bindi M., Carozzi M., Cavalli D., Conant R., Dorich C.D., Doro L., Ehrhardt F., and Farina R., 2017. Review and analysis of strengths and weaknesses of agroecosystem models for simulating $\mathrm{C}$ and $\mathrm{N}$ fluxes. Sci. Total Environ., 598, 445-470.

Eastman C.M., 2011. Soil physical characteristics of an aeric ochraqualf amended with biochar. Dissertation, Environmental and Natural Resources Program. Ohio State University. http://rave.ohiolink.edu/etdc/view?acc_num=osu1316548127

Gardner W.H., 1986. Water content. In: Methods of Soil Analysis. Part 1. Physical and Mineralogical Methods (Ed. A. Klute) American Society of Agronomy and Soil Science Society of America, Madison, WI, 493-544. https://doi. org/10.2136/sssabookser5.1.2ed.c21

Greenland D.J., 1977. Soil damage by intensive arable cultivation: temporary or permanent? Philosophical Transactions of the Royal Society B. Biological Sciences, 281(980), 193208. https://doi.org/10.1098/rstb.1977.0133 
Hansen V., Müller-Stöver D., Ahrenfeldt J., Holm J.K., Henriksen U.B., and Hauggaard-Hardie M., Clothier B., Bound S., Oliver G., and Close D., 2014. Does biochar influence soil physical properties and soil water availability? Plant and Soil, 376(1-2), 347-361. https://doi. org/10.1007/s11104-013-1980-x

Hardie M., Clothier B., Bound S., Oliver G., and Close D., 2014. Does biochar influence soil physical properties and soil water availability? Plant Soil, 376, 347-361.

Herath H.M.S.K., Camps-Arbestain M., and Hedley M., 2013. Effect of biochar on soil physical properties in two contrasting soils: an Alfisol and an Andisol. Geoderma, 209-210, 188-197. https://doi.org/10.1016/j.geoderma.2013.06.016

Jeffery S., Verheijen F.G.A., Van Der Velde M., and Bastos A.C., 2011. A quantitative review of the effects of biochar application to soils on crop productivity using meta-analysis. Agric., Ecosys. Environ., 144(1), 175-187. https://doi. org/10.1016/j.agee.2011.08.015

Jien S.H. and Wang C.S., 2013. Effects of biochar on soil properties and erosion potential in a highly weathered soil. Catena, 110, 225-233. https://doi.org/10.1016/j.catena.2013.06.021

Leij F.J., van Genuchten M.Th., Yates S.R., Russel W.B., and Kaveh F., 1992. RETC: a computer program for analyzing soil water retention and hydraulic conductivity data. In: Proc. Int. Workshop on Indirect Methods for Estimating the Hydraulic Properties of Unsaturated Soils (Eds M.Th. van Genuchten, F.J. Leij, L.J. Lund) (Riverside, CA, October 11-13, 1989). Riverside, CA, U.S. Salinity Laboratory, Agric. Res. Service, U.S. Dept. of Agriculture, 263-272. https://catalog.hathitrust.org/Record/002876644

Lal R., 2004. Soil carbon sequestration impacts on global climate change and food security. Science, 304(5677), 1623-1627. https://doi:10.1126/science.1097396

Lal R., 2007. Carbon sequestration. Philosophical Transactions of the Royal Society B. Biological Sciences, 363(1492), 815830. https://doi.org/10.1098/rstb.2007.2185

Lal R., 2009. Challenges and opportunities in soil organic matter research. Eur. J. Soil Sci., 60(2), 158-169. https://doi. org/10.1111/j.1365-2389.2008.01114.x

Marquardt D.W., 1963. An algorithm for least-squares estimation of nonlinear parameters. J. Soc. Industrial Appl. Mathematics, 11(2), 431-441. https://doi.org/10.1137/0111030

Mukherjee A. and Lal R., 2013. Biochar impacts on soil physical properties and greenhouse gas emissions. Agronomy, 3(2), 313-339. https://doi.org/10.3390/agronomy3020313

Müller F., Peukert W., Polke R., and Stenger F., 2004. Dispersing nanoparticles in liquids. Int. J. Mineral Proc., 74S, S31-S41. https://doi.org/10.1016/j.minpro.2004.07.023

Ohu J.O., 1985. Peatmoss Influence on Strength, Hydraulic Characteristics and Crop Production of Compacted Soils.
Dissertation, Department of Agricultural Engineering, McGill University, Sainte-Anne-de-Bellevue, QC, http:// digitool.Library.McGill.CA:80/R/-?func=dbin-jump-full\& object_id=71960\&silo_library $=$ GEN01

Rasoulzadeh A., 2010. Evaluation of water retention functions by developing a code for quantifying the hydraulic functions of unsaturated soils. J. Food, Agric. Environ., 8, 1180-1184. https://www.pc-progress.com/Documents/programs/retc. pdf.

Smith P., Davis S.J., Creutzig F., Fuss S., Minx J., Gabrielle B., Kato E., Jackson R.B., Cowie A., Kriegler E., van Vuuren D.P., Rogelj J., Ciais P., Milne J., Canadell J.G., McCollum D., Peters G., Andrew R., Krey V., Shrestha G., Friedlingstein P., Gasser T., Grübler A., Heidug W.K., Jonas M., Jones C.D., Kraxner F., Littleton E., Lowe J., Moreira J.R., Nakicenovic N., Obersteiner M., Patwardhan A., Rogner M., Rubin E., Sharifi A., Torvanger A., Yamagata Y., Edmonds J., and Yongsung C., 2016. Biophysical and economic limits to negative $\mathrm{CO}_{2}$ emissions. Nature Climate Change, 6(1), 42-50. https://doi.org/10.1038/nclimate2870

Smith P., Powlson D., Glendining M., and Smith J., 1997. Potential for carbon sequestration in European soils: Preliminary estimates for five scenarios using results from long-term experiments. Global Change Biol., 3(1), 67-79. https://doi.org/10.1046/j.1365-2486.1997.00055.x

Stahl K., Neergaard M., and Nieminen J., 2000. Progress Report: Varnamo biomass gasification plant. Proceedings of 1999 Gasification Technologies Conf., San Francisco, October 17-20, California, USA. URL: https://www.globalsyngas.org/uploads/eventLibrary/GTC99290.pdf

Tryon E.H., 1948. Effect of charcoal on certain physical, chemical, and biological properties of forest soils. Ecological Monographs, 18(1), 81-115. https://doi.org/10.2307/1948629

van Genuchten M.Th., 1980. A closed-form equation for predicting the hydraulic conductivity of unsaturated soils. Soil Sci. Soc. Am. J., 44(5), 892-898.

van Genuchten M.Th., Leij F.J., and Yates S.R., 1991. The RETC code for quantifying the hydraulic functions of unsaturated soils, Version 1.0. EPA Report 600/2-91/065, U.S. Salinity Laboratory, USDA-ARS, Riverside, California.

Woolf D., Amonette J.E., Street-Perrott A., Lehmann J., and Joseph S., 2010. Sustainable biochar to mitigate global climate change. Nature Communications, 1, Article 56. https:// doi.org/10.1038/ncomms 1053 